Original Contribution

\title{
AN ANALYSIS OF RURALITY INDEX IN ROMANIAN COUNTRYSIDE BY A QUANTITATIVE APPROACH
}

\author{
N. Galluzzo* \\ Association of Geographical and Economic Studies in Rural Areas (ASGEAR), Rieti, Italy
}

\begin{abstract}
Romanian rural areas have suffered a significant emigration in particular in the early 1990s. The transition from a centralised economy to an open one and the enlargement of the European Union in 2007 has been the most important factors influencing the rural depopulation. The aim of this paper was to asses by a quantitative approach an index of rurality able to estimate which variables have impacted on the socio-economic growth in Romanian rural areas. The method of investigation has used the Partial Least Square Structural Equation Modelling (PLS-SEM) able to assess in depth the cause-effect relationships among different socio-economic variables towards the rurality in Romania since 1994 to 2016. Results have pointed out a positive role of parameters correlated to the rurality such as financial subsidies allocated by the Common Agricultural Policy (CAP) and by the second pillar of the CAP aimed at stimulating the rural diversification in Romanian farms. In conclusion, for the future it is important to foster financial subsidies to Romanian farms and in particular stimulating by financial initiatives and measures farmers in stayed behind rural areas which need supports in order to lessen partially the outemigration and socio-economic marginalization in rural territories.
\end{abstract}

Key words: Common Agricultural Policy, emigration, rural areas, rural development, Structural Equation Modelling.

\section{INTRODUCTION}

Romanian rural areas have suffered more than the urban territories of an intense permanent emigration as a consequence of the collapse of a centralized economy due to the transition towards an open economy in the early 1990s. This phenomenon has been less concentrated in the region of Bucharest-Ilfov where high has been a process of internal migration from rural to urban areas. $(1,2)$. By contrast more intense has been the emigration in rural depressed territories and in stayed behind areas close to the border of Moldavia and in other rural and agrarian territories close to Bulgaria where higher is the percentage of population at risk of poverty or severe deprivation. $(1,2,3)$

During the phase of pre-accession and also after the enlargement of the European Union in 2007 the European Commission has increased the efforts in order to reduce a worsening of socio-economic conditions in Romanian rural

\footnotetext{
*Correspondence to: Nicola Galluzzo, Association of Geographical and Economic Studies in Rural Areas (ASGEAR), Via Salaria per

L'Aquila, 76 scala A, Rieti, Italy, email: asgear@libero.it
}

areas allocating specific funds aimed at getting better the socio-economic fabric and the competitiveness of enterprises. $(4,5,6,7,8,9)$ Since the enlargement of the European Union in 2007, the National Rural Development Programme and the first pillar of the Common Agricultural Policy have allocated payments and financial supports focused in stimulating the diversification in Romanian farms with the purpose to reduce the socio-economic marginalization in rural areas by agritourism, rural tourism and other traditional activities in tightly connection to agricultural and rural traditions in the framework of multifunctionality and pluriactivity able to solve partially the squeezing of farm's income. $(1,8,10,11)$

The main purpose of an index of rurality is to define a model able to asses which socioeconomic variables have had an effect on the development patterns in rural areas and also to decide the optimal allocation of financial resources and other socio-economic variables in order to reduce the socio-economic marginalization in some rural areas. Many authors have argued about the specific role of a 
rural index as a tool able to give importance to some priorities fundamental in a socioeconomic and political decision process in several European countries such as England, Wales, in small Spanish rural areas and in nonEuropean countries such as China. $(12,13,14$, 15) Some of these latter scholars have compared results of two census pointing out as the higher is the index of rurality the higher is the level of socio-economic marginalization. (12).

Several scholars have focused their attention to a model of rurality comparing two Census datasets throughout a quantitative model based on the Principal Component Analysis (PCA) able to assess some environmental and health parameters and few socio-economic variables part of a wider frame of rurality. (14) By contrast, some studies have used in a quantitative approach as proposed by Kendall in 1975, a correlation analysis and the Local Indicator of Spatial Association (LISA) which have been two methodologies pivotal in assessing a spatial association of rurality index over the time comparing in their researches different areas of investigation. $(12,16,17,18$, 19)

A comparison among different studies carried out in several European countries has underlined the strategic role of quantitative methodologies in investigating index of rurality and the insight of the rurality index has been predominately based on the Principal Component Analysis which is able to investigate in depth the main aspects and changes in rural areas. $(14,15,20)$ In literature review, lots of scholars have used a quantitative approach in order to investigate in rural areas some health factors able to act on the socio-economic context in rural territories comparing these research outcomes to other assessed in urban spaces but not so common have been studies carried out in order to analyse socio-economic and demographic factors involved in a holistic definition of rurality index. $(21,22)$ One of the reason of this lack in defining an index of rurality can be ascribed to a non-univocal definition of rural because of different variables used in the process of explanation of the meaning of rural (23); hence, the variable space is the unique and one of the most important factor in order to discriminate what is rural.

In general, the rural index as proposed by Cloke in 1977 is a pivotal tool in investigating rural areas and in defining the concept of rural and also in defining some strategies for a holistic and cohesive rural development as
GALLUZZO N. assessed by other authors with some specific implementations in a quantitative approach. $(13,24,25)$ The definition and elaboration of an index of rurality based on the assessment of the impact of financial subsidies allocated by the first and second pillar of the Common Agricultural Policy (CAP) is not so common in literature and in the same time not so widespread are quantitative models able to assess other socio-economic variables correlated to the rural context such as permanent emigration, financial subsidies allocated to the social welfare and social protection, pluriactivity and unit of research and researchers involved as well.

A quick recent literature analysis in Italy addressed at investigating in depth the definition of indicators for the assessment of rural development by identifying a specific rural index has highlighted the importance of several variables estimated in some less favored areas by a quantitative model such as the multiple regression model and the principal component analysis. $(26,27)$ These models ended up defining the social and economic variables linked to the multifunctionality and pluriactivity in farms supported by financial subsidies allocated by the second pillar of the CAP have shown a certain significance of European Union funds allocated by the Community Agricultural Policy in the socioeconomic development of rural areas. Both the quantitative multiple regression model and also the Principal Component Analysis have estimated the main statistically significant relationships among variables linked to the rurality but they do not allow to assess if there are cause-effect relationships able to enhance or to weaken its effect in a pattern of rural development emphasizing the relationship between variables correlated in the process of defining a rural development indicator. $(1,3$, 8).

\section{AIM OF THE RESEARCH}

The purpose of this research was to estimate by a quantitative approach the cause-effect relationships of some socio-economic variables on the rurality in Romania since 1994 to 2016. The quantitative approach aims to estimate the direct, indirect cause-effect relationships in a rural index is the Structural Equation Model. This method is able to assess some causeeffect relationships among a set of variables stratified in sociological, welfare, research and rurality. The sociological variables are: density of population, emigration, net income per person and population in activity between 1565 years. The welfare variables have been 
made by graduate subsidies and unemployed financial supports disbursed by the Romanian public authorities; the research variables are number of people employed in the research sector, units of research and students enrolled in the secondary schools. The set of variables linked to the rurality have been made by number of agritourism, size of farms in terms of usable agricultural area, number of animals per hectare of agricultural surface and financial subsidies allocated by the European Union in the first and second pillar of the Common Agricultural Policy as investigated by the Farm Accountancy Data Network on a sample of Romanian farms.

\section{METHODOLOGY}

A literature review has pointed out as lots of authors have investigated the rurality defining a quantitative model based on some geographical, economic and social variables and the Principal Component Analysis and the multiple regression models have been pivotal in a complete factorial analysis useful in defining the rurality in a quantitive index. (12, 13, 14). Rusu in 2017 throughout an analysis of some parameters correlated to the rurality such as the variables population density, agricultural area and people employed in the primary sector. (28) In a region of Romania, Puia in 2011 has carried out by a sociologic approach the estimation of the rurality index using as indicator some agricultural and demographic variables pointing out also the role of an urban centre in promoting the development of rural areas (29); by contrast, other studies have argued the role of the network analysis in the definition and assessment of an index of rurality. (30) Some scholars in Italy have emphasized the positive role and direct impact of few variables correlated to the pluriactivity in farms and to the financial subsidies allocated by the European Union supporting the socioeconomic development of rural areas in particular towards small farms located in less favored territories. $(26,27)$ In this analysis it has used the dataset published by the Romanian Statistical Institute TEMPO time series on the website of the institute. (2) The source of data about the financial subsidies allocated by the Common Agricultural Policy has used the data available in the Farm Accountancy Data Network (FADN) which is an annual survey carried out by the European Union in order to assess the role and impact of the Common Agricultural Policy to the European farmers.
In order to esti to define also a provisional model able to define which variables act on the rurality the Structural Equation Modelling (SEM) is particularly adequate. In general, the Structural Equation Model is based on a parametric approach which needs of particular assumptions, more variables and so on. In this paper have been assessed few variables and because of this model has been a predictive model the SEM is not adequate. (31) In order to tackle these bottlenecks in the methodology it has used the Partial Last Square Structural Equation Model (PLS-SEM) by Smart-PLS version 3.2.7 student licence.

The Structural Equation Modelling is able to describe the causality among latent variables. It is an iterative methodology aims at estimating the internal and external weights and values of latent variables. The partial estimation is made by different blocks of variables one at a time alternating simple regressions and multiple regressions as well; the assessment of latent variables is calculated by the alternation of inner and outer iterated estimations till the point of convergence and the path coefficients as estimated in a tradition regression approach of latent variables in estimated values. $(31,32,33)$ In general, in the Structural Equation Model it is possible to find and to estimate two different sub models such as the inner one made by the interactions between the dependent and independent variables and the outer model based on the main relationships between latent variables and their factors or indicators. (32) The variables in Structural Equation Model are classified as exogenous with path arrows pointing outwards and they do not receive any other arrows instead the endogenous variables have made by one or more arrows leading to it. $(31,32,33$, 34)

As mentioned above, the PLS-SEM is a nonparametric model due to its own not restrictive underlying assumptions able to estimate the main correlations and links among variables when the sample is made by a modest sample size, furthermore not so common is the theory able to be investigated, the predictive accuracy is fundamental, it is not important having constraints correlated to well defined measurement scale and it is harsh to define correct model specifications in the model. (32, 34)

The PLS-SEM is adequate in estimating some relationships in a small sample even if a dimension of 100 to 200 units is fundamental 
hence, the poorer is the number of samples more modest quality are the results. $(32,35)$

The PLS Path Modeling does not need some strong assumptions about the distribution of normality in the investigated people or correlated to the unit of measurement even if the dataset has to be standardized in order to simplify the model which is based on two only parameters such as the average and the variance comparing also the variables stratified as homogeneous variables. (36).

Furthermore, the standardization is pivotal in doing some goodness and statistical significance of all possible solutions in the model. Because of non-normality of all investigated variables in this paper it has used a non-parametric test such as the bootstrap which is a statistical inference on a resampling in all variables and it is more robust than the other techniques of resampling such as the jacknife in term of $t$ test. (36) According to this author, the bootstrapping changes completely the original sample every time in each phase of resampling between new and old samples that have also the same size and if the $t$ test is not significant with a $\mathrm{p}$ value higher than $5 \%$ this implies that resampling values are completely different from the initial sample and they are also totally far from the initial sample.

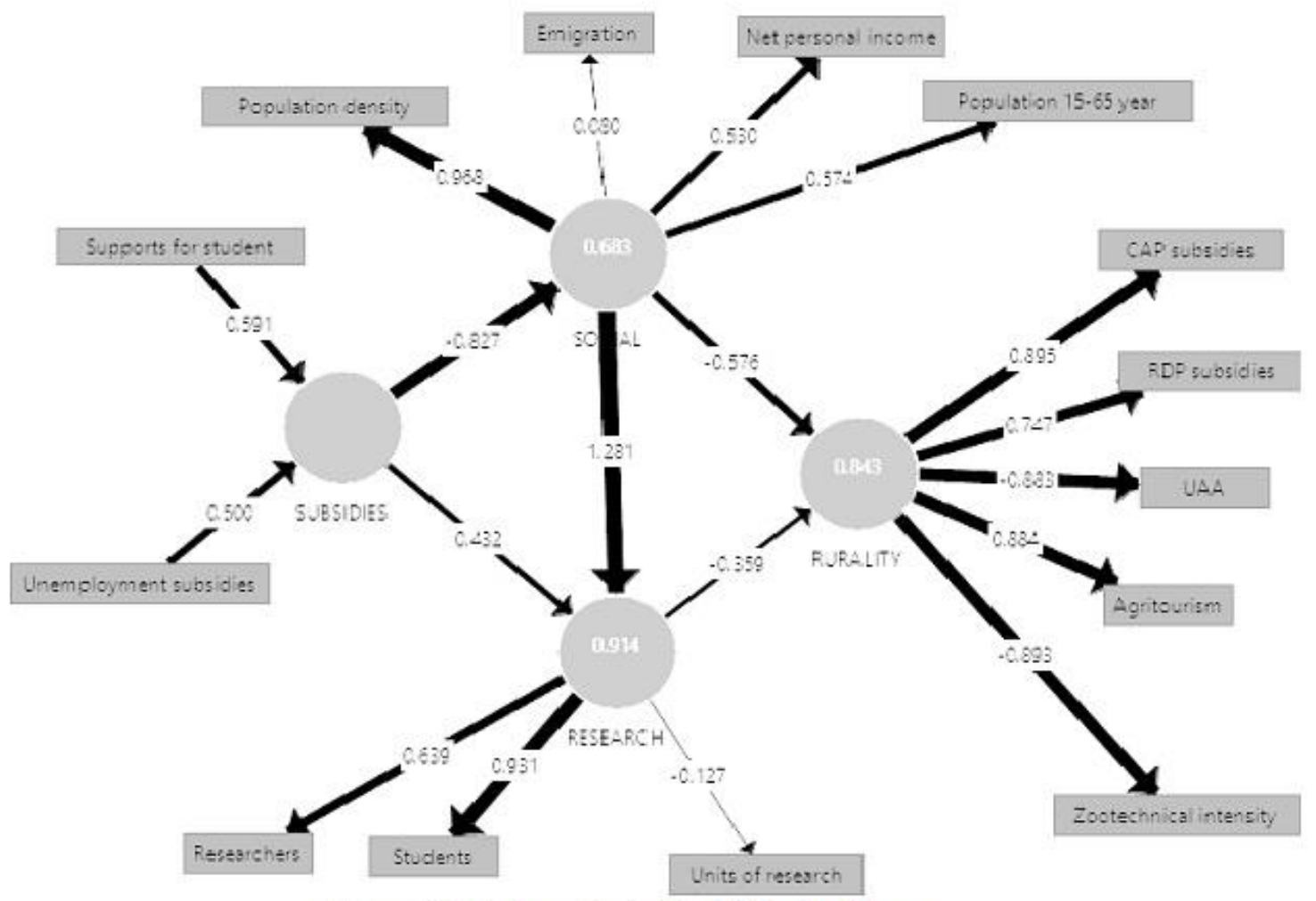

Figure 1. Main results in the PLS path diagram

(Source author's elaboration on data FADN published on the web site http://ec.europa.eu/agriculture/rica/database/database_en.cfm and Romanian Institute of Stati stics TEMPO tile series published on the website http://statistici.insse.ro)

\section{RESULTS}

The highest levels of $\mathrm{R}^{2}$ have been estimated in the endogenous latent variables research and rurality equal to 0.91 and 0.84 which implies as more than $80 \%$ of variance is explained by the quantitative PLS model (Figure 1). Social variable has a more significant indirect impact on the variable rurality than the endogenous variable research equal to -0.57 and -0.35 even if only the endogenous variable social has had a statistical impact with a $p$ value equal to 0.02 hence, lower than $5 \%$. The thickness of arrows in direct and indirect effects has pointed out the different role of population density, CAP subsidies and financial payments supports towards students. No effects of subsidies allocated towards unemployed people.

The variables social and research, in particular this latter variable, have had a direct impact on the variable rurality. This endogenous variable has been statistically significant towards the variables social and research even if findings in many standardized path coefficients have not pointed out values lower than 0.01 .

In the inner model, all investigated variables connected to the rurality such as financial 
subsidies allocated by the Common Agricultural Policy (CAP) and by the Rural Development Plan (RDP) have had a significant impact on the rurality with a $p$ value $<0.001$. In the same time the variable agritourism has been pivotal in influencing the rurality in Romania over the time of investigation.

The level of $\rho$ have been above the value of 0.78 and in particular the endogenous variables rurality and subsidies allocated for rural development and by the CAP have had a value of liability above the threshold proposed by some author in the case of an exploratory research, equal to 0.4. (37)

The AVE has been higher than 0.5 in the endogenous variables as proposed by Bagozzi and $\mathrm{Yi}$ in 1988 (38); the Convergent validity expresses as Composite Reliability has been above 0.5 in the endogenous variables research and social. (32).

\section{CONCLUSION}

The PLS-SEM is not so common in researches about rural economy and in this paper, it seems partially adequate to define a quantitative method aimed at assessing the rurality and some socio-economic variables acting on it. Findings in this research have pointed out a positive and direct impact of financial subsidies allocated by the first and second pillar of the Common Agricultural Policy in reducing the socio-economic marginalization in rural areas. This implies demanding efforts by national and European authorities in stimulating the number of financial subsidies allocated both in supporting the rural development and also the diversification of activities in Romanian farms stimulating financial aids and direct payments towards research and students. The size of farms in terms of usable agricultural areas has corroborated its own role in defining the conceptualization of rurality as argued by other scholars in some European countries.

\section{REFERENCES}

1. Galluzzo, N., Gross Domestic Product and rural depopulation in Romania: analysis of correlations using a quantitative approach. Agricultural Economics and Rural Development, 14(1), 23-36, 2017 a.

2. INSEE (Romanian Institute of Statistics), TEMPO time series. Retrieved from http://statistici.insse.ro, (03.01.2018).

3. Galluzzo, N., The Common Agricultural Policy and employment opportunities in Romanian rural areas: the role of agritourism. Bulgarian Journal of Agricultural Science, 23(1), 14-21, $2017 \mathrm{~b}$.

4. Galluzzo, N., Role and effect of agroforestry subsides allocated by the Common Agricultural Policy in Italian farms. International Journal of Food and Agricultural Economics, 3(1), 19-31, 2015a.

5. Galluzzo, N., Analysis of impact of rural development subsides on cropping specialization in Bulgaria and Romania using FADN data. In: Proceedings of $150^{\text {th }}$ EAAE Seminar, 22-23 October 2015, Edinburg, Scotland, 2015b.

6. Galluzzo, N., Role of financial subsidies allocated by the Common Agricultural Policy in reducing out emigration in Italian countryside. Romanian Journal of Regional Science, 10(2), 50-63, 2016a.

7. Galluzzo, N., Analysis of financial subsidies allocated by the common agricultural policy to European farms in reducing economic-territorial inequalities by indexes of concentration. Studia Universitatis Babes-Bolyai, Geographia, 61(1), 27-38, 2016b.

8. Galluzzo, N., Efficiency analysis in different typologies of farming in Italian FADN dataset. Ekonomika Poljoprivrede, 64(2), 451-465, 2017c.

9. Cionga, C., Luca, L., and Hubbard, C., The impacts of direct payments on Romanian farm income: who benefits from the CAP? Lucrare pregătita pentru Seminarul, 109, 20-21, 2008.

10. Van der Ploeg, J.D., Long A. and Banks J., Living Countrysides: Rural Development Processes in Europe: the State of the Art. Amsterdam, Elsevier EBI. pp. 231, 2002.

11.Davis, J., Rural non-farm livelihoods in transition economies: emerging issues and policies. Electronic Journal of Agricultural and Development Economics, 3(2), 180224, 2006.

12.Li, Y., Long, H., and Liu, Y., Spatiotemporal pattern of China's rural development: A rurality index perspective. Journal of Rural Studies, 38, 12-26, 2015.

13. Cloke, P. J., An index of rurality for England and Wales. Regional Studies, 11(1), 31-46, 1977.

14.Prieto-Lara, E., and Ocaña-Riola, R., Updating rurality index for small areas in Spain. Social Indicators Research, 95(2), 267, 2010.

15.Ocaña-Riola, R., and Sánchez-Cantalejo, C., Rurality index for small areas in Spain. Social Indicators Research, 73(2), 247-266, 2005. 
16.Kendall, M. Multivariate analysis. London, Charles Griffin \& Company Limited. pp. 210, 1975.

17.Lehtonen, O., and Tykkyläinen, M., Selfreinforcing spatial clusters of migration and socio-economic conditions in Finland in 1998-2006. Journal of Rural Studies, 26(4), 361-373, 2010.

18. Anselin, L., Syabri, I. and Kho, Y., GeoDa: an introduction to spatial data analysis. Geographical Analysis, 38 (1), 5-22, 2006

19.Griffith, D. Spatial auto correlation and spatial filtering. Gaining understanding through theory and scientific visualization. Berlin, Springer. pp. 247, 2003.

20.Cloke, P., and Edwards, G., Rurality in England and Wales 1981: a replication of the 1971 index. Regional Studies, 20(4), 289-306, 1986.

21.Weinert, C., and Boik, R.J., MSU rurality index: development and evaluation. Research in nursing \& health, 18(5), 453464, 1995.

22.Olatunde, S., Leduc, E.R., and Berkowitz, J., Different practice patterns of rural and urban general practitioners are predicted by the General Practice Rurality Index. Canadian Journal of Rural Medicine, 12(2), 73-80, 2007

23.Halfacree, K.H., Locality and social representation: space, discourse and alternative definitions of the rural. Journal of rural studies, 9(1), 23-37, 1993.

24.Banister, D., Transport mobility in interurban areas: A case study approach in South Oxfordshire. Regional Studies, 14(4), 285-296, 1980.

25.Harrington, V., and O'Donoghue, D., Rurality in England and Wales 1991: a replication and extension of the 1981 rurality index. Sociologia Ruralis, 38(2), 178-203, 1998.

26.Finco, A., Pronio, G.D., and Pollonara, M., Multifunzionalità e sviluppo rurale delle zone montane. Rivista di Economia Agraria, 60(2), 449-468, 2005.

27.Galluzzo, N., The impact of II pillar on the multifunctionality in Italian farms: analysis on the farm holidays. In: Proceeding of $109^{\text {th }}$ Seminar European Association of Agricultural Economists, November 20-21, 2008, Viterbo, Italy, 2008.

28.Rusu, M., Rurality and competitiveness typologies: analysis at the county level in Romania. Scientific Papers SeriesManagement, Economic Engineering in
GALLUZZO N.

Agriculture and Rural Development, 17(1), 367-374, 2017.

29.Puia, O.A., The evaluation of rural space through the analysis of the rurality index. Case study: the villages of Sălaj East of Jibou. Forum geographic, 10(2), 264-275, 2011.

30.Braga, G.B., Remoaldo, P.C., and Fiúza, A.L.C., Rurality index: a state-of-the-art network view. In: The overarching issues of the European space: spatial planning and multiple paths to sustainable and inclusive development. Porto. FLUP, pp. 298-314, 2013.

31.Hair J.F, Hult, G.T.M., Ringle, C.M., and Sarstedt, M. A primer on practical least squares structural equation modelling. Second Edition. London, Sage publications Ltd. pp. 363, 2016.

32.Wong, K.K.K., Partial least squares structural equation modelling (PLS-SEM) techniques using SmartPLS. Marketing Bulletin, 24(1), 1-32, 2013.

33.Vinzi, V.E., Trinchera, L., and Amato, S., PLS path modelling: from foundations to recent developments and open issues for model assessment and improvement. In: Handbook of partial least squares, Springer, Berlin, Heidelberg, De, pp. 48-82, 2010.

34.Awang, Z., Afthanorhan, W.M.A.W., and Asri, M.A M., Parametric and non parametric approach in structural equation modelling (SEM): The application of bootstrapping. Modern Applied Science, 9(9), 58-67, 2015

35.Hoyle, R.H., Structural equation modeling: Concepts, issues, and applications. London, Sage publications Ltd. pp. 312, 1995

36.Guazzo, V., Customer satisfaction: sviluppo di metodologie statistiche per la sua misurazione con particolare applicazione alle aziende di trasporto pubblico. PhD thesis on the website http://www.fedoa.unina.it/3489/1/Tesi_Dott orato_Statistica_Guazzo_velia.pdf, 2008.

37.Hulland, J., Use of partial least squares (PLS) in strategic management research: a review of four recent studies. Strategic Management Journal, 20(2), 195-204, 1999.

38.Bagozzi, R.P., and Yi, Y., On the evaluation of structural equation models. Journal of the Academy of Marketing Science, 16(1), 74-94, 1988. 